\title{
Dynamic analysis using finite elements to calculate the critical wear section of the contact wire in suburban railway overhead conductor rails
}

\author{
F.J. Gonzalez, J.A. Chover, B. Suarez and M. Vazquez
}

The purpose of this study is to determine the critical wear levels of the contact wire of the catenary on metropolitan lines. The study has focussed on the zones of contact wire where localised wear is produced, normally associated with the appearance of electric arcs. To this end, a finite element model has been developed to study the dynamics of pantograph-catenary interaction. The model includes a zone of localised wear and a singularity in the contact wire in order to simulate the worst case scenario from the point of view of stresses. In order to consider the different stages in the wire wear process, different depths and widths of the localised wear zone were defined. The results of the dynamic simulations performed for each stage of wear let the area of the minimum resistant section of the contact wire be determined for which stresses are greater than the allowable stress. The maximum tensile stress reached in the contact wire shows a clear sensitivity to the size of the local wear zone, defined by its width and depth. In this way, if the wear measurements taken with an overhead line recording vehicle are analysed, it will be possible to calculate the potential breakage risk of the wire. A strong dependence of the tensile forces of the contact wire has also been observed. These results will allow priorities to be set for replacing the most critical sections of wire, thereby making maintenance much more efficient. The results obtained show that the wire replacement criteria currently borne in mind have turned out to be appropriate, although in some wear scenarios these criteria could be adjusted even more, and so prolong the life cycle of the contact wire.

\section{The final, definitive version of this paper has been published in Proceedings of the Institution of Mechanical Engineers, Part F: Journal of Rail and Rapid Transit, Vol. 222, Issue 2, 2008 by SAGE Publications Ltd. All rights reserved (C.}

The published version of this paper is available online at: http://pif.sagepub.com/content/222/2/145

DOI: 10.1243/09544097JRRT144

When citing this work, please refer to the published paper:

$$
\begin{aligned}
& \text { F.J. Gonzalez, J.A. Chover, B. Suarez and M. Vazquez, Dynamic } \\
& \text { analysis using finite elements to calculate the critical wear section of the } \\
& \text { contact wire in suburban railway overhead conductor rails. Proc. } \\
& \text { IMechE Part F: Journal of Rail and Rapid Transit, Vol. 222, pp. 145- } \\
& \text { 157, 2008. }
\end{aligned}
$$




\title{
Dynamic analysis using finite elements to calculate the critical wear section of the contact wire in suburban railway overhead conductor rails
}

\author{
F.J. Gonzalez ${ }^{1}$, J.A. Chover ${ }^{2}$, B. Suarez ${ }^{2 *}$ and M. Vazquez ${ }^{1}$ \\ ${ }^{1}$ Metro de Madrid S.A., Madrid, Spain \\ ${ }^{2}$ Railway Technologies Research Centre (CITEF), Universidad Politecnica de Madrid, Madrid, Spain \\ * Corresponding author: CITEF, C/ José Gutiérrez Abascal nº 2, ES-28006 Madrid, Spain, email: \\ citef.bsuarez@etsii.upm.es
}

Synopsis: The purpose of this study is to determine the critical wear levels of the contact wire of the catenary on metropolitan lines. The study has focussed on the zones of contact wire where localised wear is produced, normally associated with the appearance of electric arcs. To this end, a finite element model has been developed to study the dynamics of pantographcatenary interaction. The model includes a zone of localised wear and a singularity in the contact wire in order to simulate the worst case scenario from the point of view of stresses.

In order to consider the different stages in the wire wear process, different depths and widths of the localised wear zone were defined. The results of the dynamic simulations performed for each stage of wear let the area of the minimum resistant section of the contact wire be determined for which stresses are greater than the allowable stress.

The maximum tensile stress reached in the contact wire shows a clear sensitivity to the size of the local wear zone, defined by its width and depth. In this way, if the wear measurements taken with an overhead line recording vehicle are analysed, it will be possible to calculate the potential breakage risk of the wire. A strong dependence of the tensile forces of the contact wire has also been observed. These results will allow priorities to be set for replacing the most critical sections of wire, thereby making maintenance much more efficient.

The results obtained show that the wire replacement criteria currently borne in mind have turned out to be appropriate, although in some wear scenarios these criteria could be adjusted even more, and so prolong the life cycle of the contact wire.

Key words: catenary, contact wire wear, pantograph-catenary interaction, tension, maintenance, dynamic analysis, simulation, finite elements

\section{$1 \quad$ Background and objectives}

\subsection{Introduction}

Urban railways are differentiated from regional and intercity railway systems, among other things, by their slower running speed, which is not usually greater than $80 \mathrm{~km} / \mathrm{h}$. As lower voltages are required to move the trains, the lines are electrified with direct current at voltages ranging from 600 to $3000 \mathrm{~V}$. The vehicle collects the electric current via the pantograph strip, which slides along the 
contact wire of the overhead line. As the lines are electrified under low voltage, they demand greater current intensities than other types of railway systems, and this can lead to the overhead line overheating.

Maintenance work is hindered, to a large extent, by the high density of traffic. On the one hand, wear due to mechanical abrasion increases, while at the same time there is a demand for continuous current consumption, which increases the risk of overheating, which in turn alters the mechanical properties of the material. On the other hand, this means that maintenance work has to be done outside working hours, only a few hours being available during the night (often no more than two) [1].

The rapid evolution of wire wear combined with the little time available for maintenance work conditions the amount of wear that is acceptable before replacing the wire. Thus, in metropolitan operations, wear levels of over $50 \%$ of the original section are admitted, in comparison to the $20 \%$ admitted by other types of administrations [2]. At certain critical points on the line it is normal for local wear to appear that usually exceeds the mean level, forcing the wire to be replaced sooner than estimated.

Excessive wire wear can lead to breakage causing the service to be suspended. The costs linked to a service being suspended can be extremely high, although the most important factor is the repercussion on the passengers affected. Therefore, it is very important to find a compromise that will allow maximum usage of the wire without entailing any risk of breakage.

The importance of adequate planning may be deduced from the above with regard to overhead line maintenance in metropolitan operations. The work presented in this paper is the result of a collaboration project between the Railway Technology Research Centre (CITEF), of Madrid Polytechnic University, (UPM), and the Metro de Madrid Maintenance Engineering and R+D Department when Metro planned to improve overhead line maintenance operations by identifying the sections to be prioritised for the replacement of excessively worn wires.

The study is focussed on the wire zones exhibiting localised wear, normally associated with the appearance of electric arcs. It is intended to determine the critical contact wire wear levels of the catenary. The overhead conductor rail electrification system has been excluded, as in this case wire breakage does not involve any risk of the service being suspended as the wire is held in place by the conductor rail.

The study could have been approached from two perspectives. On the one hand, a static analysis could have been performed, permitting the critical section to be calculated for a given tensile force. However, it was observed that the wire breaks when the train passes, for which reason it was decided to approach the study from a dynamic point of view, superimposing the dynamic effect of the pantograph-catenary interaction over the nominal tensile stress.

This paper has been structured in the following way: Section 1 presents an introduction to the problem of contact wire wear in urban railway networks; Section 2 deals with the state of the art concerning causes of wire wear; Section 3 describes the mathematical models developed to study the problem, as well as the scenarios considered in the simulations; Section 4 shows the results obtained in the study and, finally, Section 5 includes the conclusions of the presented study.

\subsection{Catenary maintenance in Metro de Madrid}

\subsubsection{Conventional maintenance methods}

Railway installations maintenance is usually corrective and preventive. This accounts for $50 \%$ of the total cost of railway companies, of which $75 \%$ corresponds to staff costs and $25 \%$ to outsourced 
services and material [1]. Currently Metro de Madrid's overhead line maintenance plan is a preventive one that sets out periodic revisions for each line, with periods ranging from 3 to 24 weeks.

Maintenance is based on visual inspection. The system employed is completely manual and requires the direct involvement of specialised personnel and vehicles. Each work team inspects 4 or 5 $\mathrm{km}$ in one night. To determine the state of wear of the contact wires, go/no go gauges are used (Figure 1). The gauges are two-phase, corresponding to two states of wire wear. When a wire is sufficiently worn to pass through the phase 2 hole (most severe), the wire is replaced. In cases of isolated wear, only a three metre long section is replaced. If the wear detected is critical, the wire is replaced there and then. If not, the incident is reported and the wire replaced within five days.

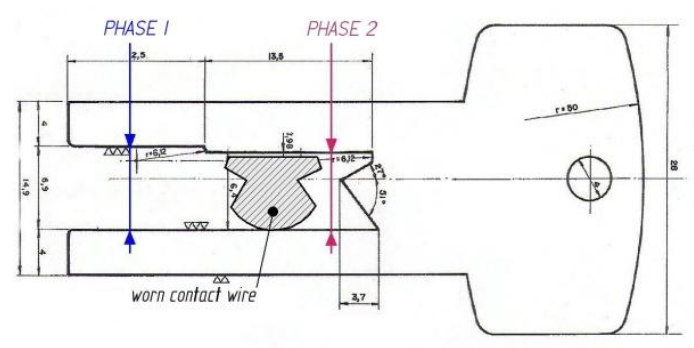

Figure 1. Using the go/no go gauge

By way of illustration, Figure 2 shows statistics on the number of maintenance operations and contact wire consumption in recent years on Line 5 (tramway wire) and Line 6 (conventional catenary). Consumption is expressed in $\mathrm{m}$ of wire replaced.
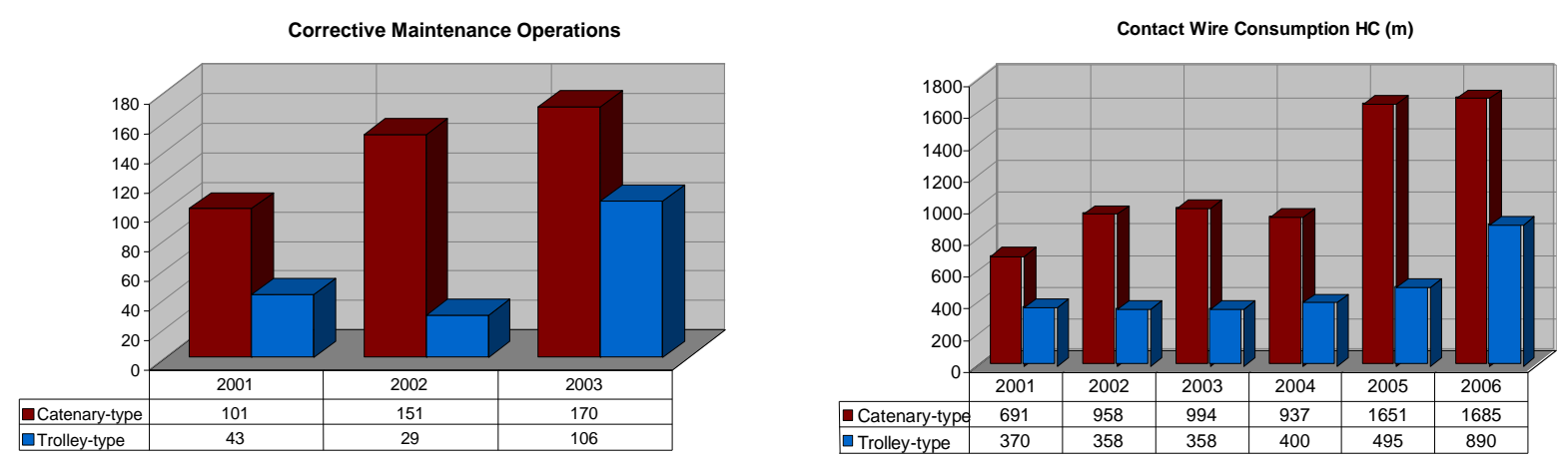

Figure 2. Contact wire replacements in Metro de Madrid

\subsubsection{New maintenance techniques}

The increase in the length of the network, which has gone from 120 to $316 \mathrm{~km}$ between 1995 and 2007 (Figure 3), combined with the ever higher standards of quality demanded by customers, means that measures have had to be taken to improve the efficacy and efficiency of maintenance operations. 


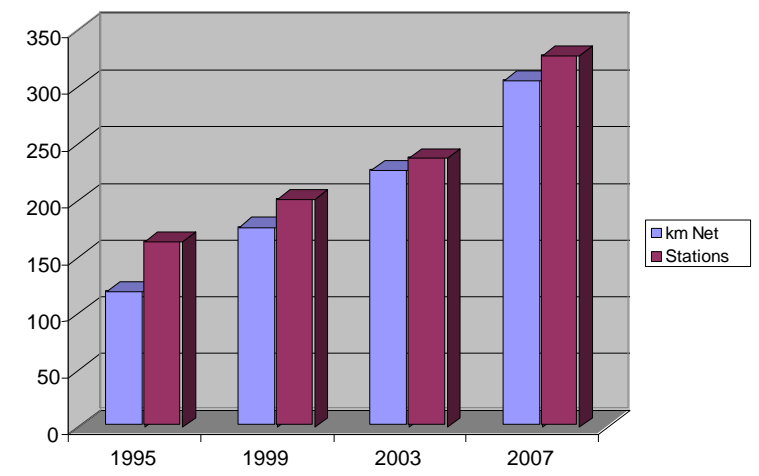

Figure 3. The expansion of Metro's network

The new techniques are tending to make visual inspections unnecessary by using predictive diagnostic methods based on measuring specific contact wire variables. This enables costs to be cut considerably with wire replacement being programmed according to regression curves which facilitate choosing the exact moment to take action. [1].

An important step forward in this sense is the latest development in non-contact measurement by optical triangulation. Using these systems, the position of the wire in service and its state of wear can be measured without having to cut off the electric power or alter the line geometry when taking measurements. Predictive operations therefore combine more easily with normal service. The subjective element is also eliminated from current maintenance methods which are based on worker criterion.

Metro de Madrid has decided to give its support to this working philosophy by bringing the latest in track and overhead line recording systems into service (Figure 4). The new recording vehicle performs a complete auscultation of the overhead line. Among other parameters, it measures the position and wear of the wire using non-contact measuring systems. It also measures the contact force between the pantograph and the overhead line.

Commissioning this vehicle has enabled a large amount of human resources and material to be made available that can now be assigned to repair work instead of inspection work.

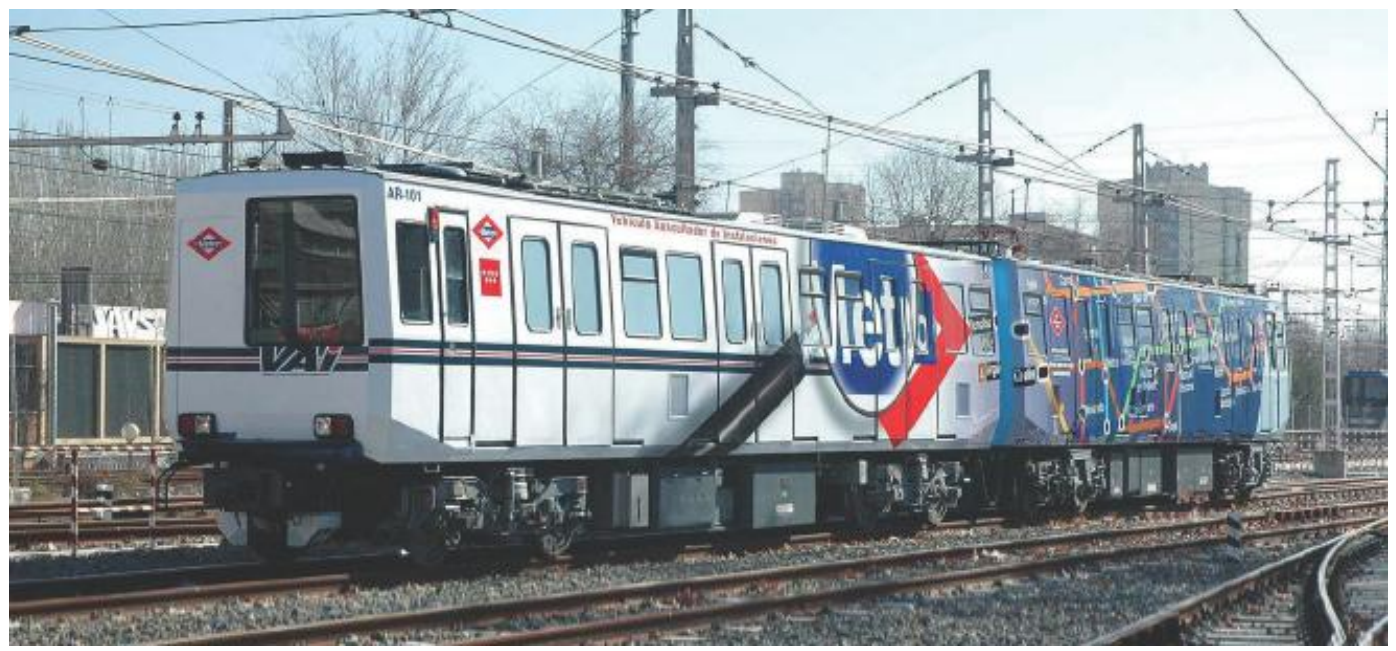

Figure 4. Infrastructure auscultation vehicle (IAV) 


\section{Main causes of contact wire wear. State of the art}

The sliding between the contact wire and the pantograph causes wear to both surfaces. For financial and safety reasons, wire wear is more critical than that of the collector strip.

Wear is due to mutually related mechanical and electrical factors. According to [3], the most influential factors are the material the wire and collector strip are made of, the contact force, the current intensity and the speed of the vehicle. Another important factor is, also, the number of pantographs collecting current at the same time.

Irregularities in the wire and particularly singular spots with local variations in stiffness, such as the suspension cable anchorage points and the registration arms, cause contact losses between the pantograph and the catenary, [3], [4], [5] and [6]. These contact losses give rise to electric arcs, which cause local overheating, with micro-melting and the evaporation of material, thereby accelerating the wear process at a local level, which means that wear is not uniform. The rise in temperature accompanying the arc produces an annealing treatment, so the worn wire becomes softer than new wires, [7], facilitating surface abrasion.

\subsection{Electric arc formation}

Contact losses can come about through kinks in the wire or through variations in the height of the catenary. [6]. Contact losses are accompanied by sudden interruptions to the stable current flow, causing a considerable voltage drop and a gradual decrease in current intensity. The voltage drop varies as the contact conditions change and the electric arc (Figure 5) is generated when the arc supersedes the minimum arc voltage [8].

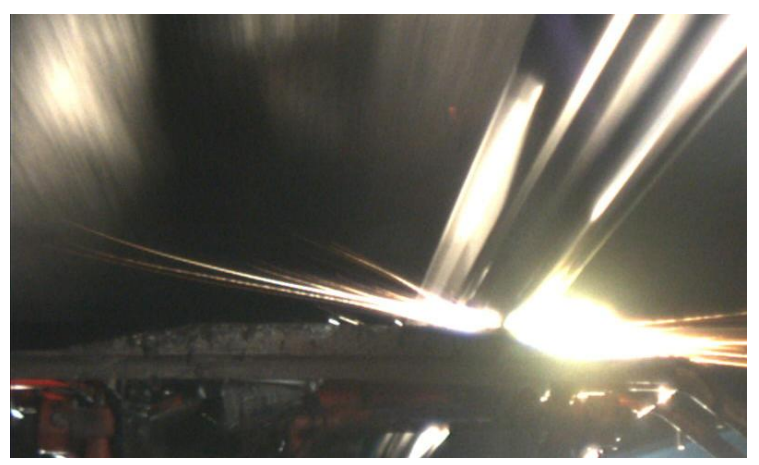

\section{Figure 5. Electric arc}

Another possible cause of electric arcs is associated with the bad quality of the sliding contact, which is called the "electrical welding" effect [6]. Surface roughness of the contact strip and the contact wire, and installation defects cause the current to be unequally distributed throughout the length of the contact surfaces. Hot spots are thus created and microweldings, which break with the forward movement of the train, giving rise to continuous sparking, [6] and [9]. These contact losses last for less than $5 \mathrm{~ms}$, which means that current collection is not hindered; however, the wire surface is seriously deteriorated.

\subsection{Wear rate}

"Wear rate" is defined as the worn volume per unit of distance travelled by the pantograph, [3] and [4]. Different studies, [2], [3] and [4], show that the contact wire wear rate depends on the heat generated on the contact surfaces and the pressure of contact between the wire and the contact strip. 
This heat is the sum of the mechanical heat associated with friction, Joule heat associated with contact electric resistance, and the heat generated by the electric arcs.

In the absence of contact losses, the main wear mechanism is mechanical abrasion, which increases with the friction force, [3]. When current intensity reaches a certain value, micro-melting is also produced, which reduces the friction coefficient and the contact electric resistance, thereby reducing the wear rate.

When contact losses occur, the main wear mechanism is electric arcs, [3]. The heat generated is considerably greater than in the other two cases. The arc plasma can reach temperatures of 3500 or $4000 \mathrm{~K}$, causing a sudden rise in temperature around the arc generation spot, leading to the copper melting and vaporising.

\subsubsection{Mechanical contribution}

According to [2] and [3], the mechanical contribution associated with wear is abrasive wear, which is proportional to the frictional power, and responds to Archard's formulation:

$$
A_{1}=k_{1}\left(\frac{i+i_{0}}{i_{0}}\right)^{-1 / n} \frac{F_{c}}{H} \frac{v}{v_{0}}
$$

Some authors, like Bruni et al. [4], consider that a non-linear relation exists with the contact force, the mechanical wear rate being expressed as:

$$
A_{1}=k_{1}\left(\frac{i+i_{0}}{i_{0}}\right)^{-\alpha}\left(\frac{F_{c}}{F_{0}}\right)^{\beta} \frac{F_{c}}{H} \frac{v}{v_{0}}
$$

where $\mathrm{k}_{1}$ is an adimensional coefficient of proportionality, $\mathrm{F}_{\mathrm{c}}$ is the contact force, $\mathrm{v}$ is the running speed, $\mathrm{H}$ is the hardness of the contact wire material, and $\mathrm{i}$ is current intensity. $\mathrm{F}_{0}, \mathrm{v}_{0}$ and $\mathrm{i}_{0}$ are reference values, used in order to be able to express some terms of the equation in an adimensional form. The corrective term depending on i takes account of the "current lubrication" effect, which reduces wear as intensity increases [4]. This is due to the fact that high intensities produce local melting which reduces the friction coefficient and redistributes the material on the contact surfaces instead of eliminating it by abrasion.

\subsubsection{Electrical contribution due to the Joule effect}

The electrical contribution associated with sparking is proportional to the electrical power dissipated in the contact, related to electric Joule heating, [2], [3] and [4]:

$$
A_{2}=\frac{k_{2} R \boldsymbol{F}_{c}: i^{2}}{H \cdot V}
$$

$\mathrm{k}_{2}$ being an adimensional coefficient of proportionality, and $\mathrm{R}$ the contact resistance, which, in turn depends on the contact force, according to the law:

$$
R \boldsymbol{F}_{c}=\frac{\rho_{c}}{2}\left(\frac{F_{c}}{\pi H}\right)^{-1 / 2}
$$

\subsubsection{Electrical contribution due to electric arc generation}

The electrical contribution associated with electric arcs is proportional to the energy of the arc. It responds to the same formulation as the Joule effect wear rate, but replacing the contact resistance by 
an air gap resistance between the wire and the contact strip [3] and [4]. The final expression adopts the form:

$$
A_{3}=k_{3} V_{a} \cdot i
$$

$\mathrm{k}_{3}$ being a constant of proportionality, and $\mathrm{V}_{\mathrm{a}}$ the voltage drop between the contact wire and the contact strip.

By letting $\varepsilon$ be the contact loss ratio, and grouping all these contributions, the total wear rate is:

$$
A_{1}=k_{1}\left(1+\frac{i}{i_{0}}\right)^{-\alpha}\left(\frac{F_{c}}{F_{0}}\right)^{\beta} \frac{v}{v_{0}} \frac{F_{c}}{H}+\mathbf{(}-\varepsilon ; \frac{k_{2} R \boldsymbol{F}_{c}-i^{2}}{H \cdot V}+\varepsilon \cdot k_{3} V_{a} \cdot i^{2}
$$

The values of constants $k_{1}, k_{2}, k_{3}, \alpha$ and $\beta$ need to be adjusted experimentally, either with a test rig or with measurements taken on an actual line.

\section{Definition of the simulation models}

\subsection{Experimental measurements}

\subsubsection{Metalographic test}

The purpose of these measurements is to assess the contact wire's tensile strength on the surface layer, since this layer may have undergone some sort of thermal treatment due to the rise in temperature caused by the electric arcs. This result will be used to define the properties of the material in FEM models developed to analyse wire stresses.

Tensile tests cannot be directly carried out on worn wires since the different sections would lead to distorted results. Neither can uniform thickness samples be used since the affected layer is the surface layer. Tensile strength could be determined according to the structure and hardness of the surface layer affected. Therefore, it was chosen to measure the thickness of this layer, checking to see if any change in material properties can be detected that might affect tensile strength.

The hardness at different surface depths was measured in a longitudinal section and in a cross section. Micrographic analyses were also performed on the most relevant zones.

Several $400 \mathrm{~mm}$ length wire samples were analysed, taken from different points of the line having rapid wear development. The samples analysed (Figure 6) showed three different degrees of wear, corresponding to a new wire, and go/no go gauge phases 1 and 2 .

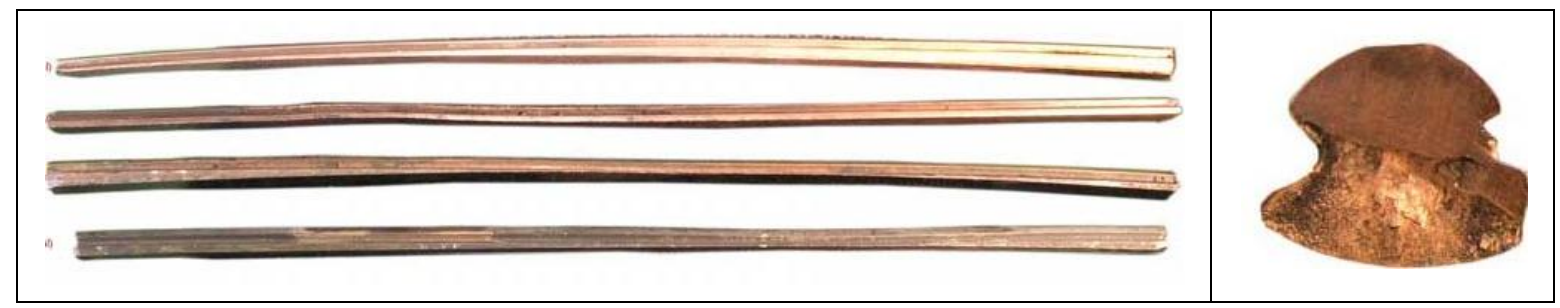

Figure 6. (left.) $107 \mathrm{~mm}^{2}$ wires in phase 1 of wear; (right) wire section

In all cases analysed hardness values were obtained equal to those for new material at a depth of $0.2 \mathrm{~mm}$ from the contact surface.

The metalographic analysis does not reveal any peculiarity in the structure of the material, except in close proximity to the wear surface. Figure 7 shows the micrographs of the longitudinal section and cross section on the wear surface. 
LONGITUDINAL SECTION

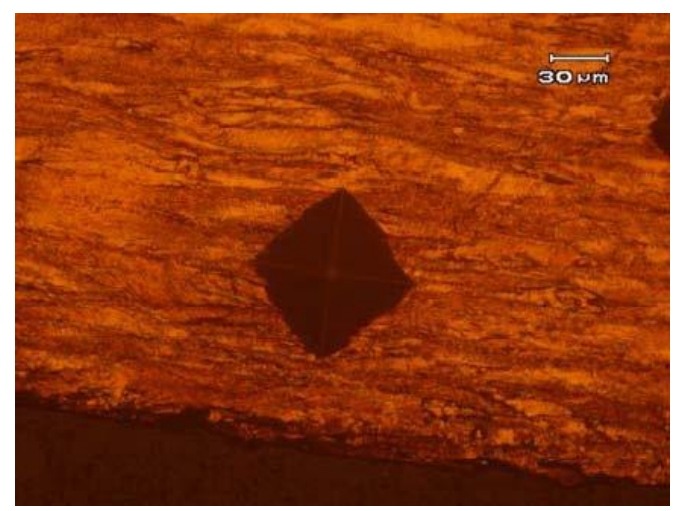

CROSS SECTION

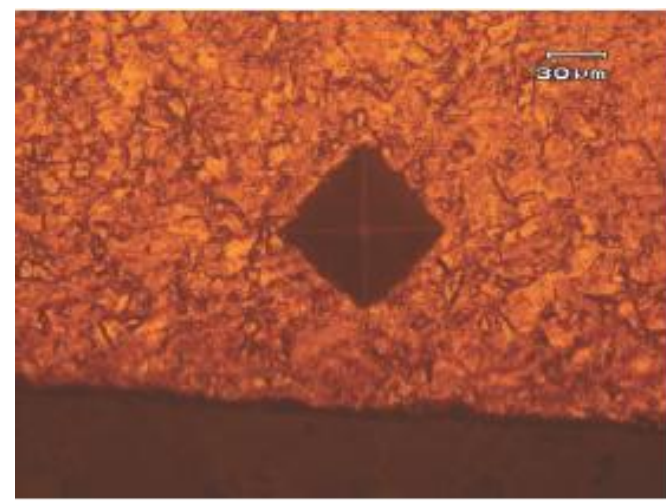

Figure 7. Micrographs of the wear surface. Longitudinal section (left) and cross section (right)

The hardness of the layer nearest the wear surface varies according to each case. In one case the copper is completely annealed, but in the majority of cases variation in hardness is not so accused. In this isolated case, in the micrograph it was observed that the layer was about to come loose, which would seem to suggest that the difference was due to the advanced state of wear. It was finally concluded that the affected zone is less than $0.2 \mathrm{~mm}$, which means that its influence on tensile strength is negligible, particularly if compared with section loss. However, the influence of this layer is decisive on the speed and type of wear produced on the contact.

\subsubsection{Characterising wear}

In order to know the geometry of the most usual local wear, wear measurements were taken for several contact wire samples with severe wear. The samples were between 1 and $2.5 \mathrm{~m}$ long. Wire thickness was measured at intervals of $10 \mathrm{~mm}$. Figure 8 shows the wear geometry obtained for one of the samples. In practically every case, a typical asymmetric bell-shaped geometry was obtained with a slight "hump" on one of its sides (see Figure 8).

An analytical expression was sought that would fit to the measurements, finally finding a family of curves that provide an excellent fitting:

$$
\left.y=a+b_{1} e^{-0.5 \cdot c_{1}\left(-d_{1} \gamma_{2}\right.}+b_{2} e^{-0.5 \cdot c_{2} \ll-d_{2}} \text {; } \quad \text { (eq. } 1\right)
$$

$a, b_{1}, c_{1}, d_{1}, a_{2}, b_{2}, c_{2}, d_{2}$ being the adjustment parameters.

This function was found by adding a constant to two exponential functions that are usually used to characterise wear on railway tracks. The analytical function can thus be adjusted both to the main bell and to the "slight hump". Constant $a$ represents uniform wear throughout the wire; $b_{1}$ and $b_{2}$ define the depth of the worn zone, and $c_{1}$ and $c_{2}$ its width.

The measurements with all the samples of this function have been fitted by minimum squares (see Figure 8), obtaining the fitting parameter values for one sample. A range of variation has thus been obtained for each parameter of the family of curves, which correspond to real wear. 


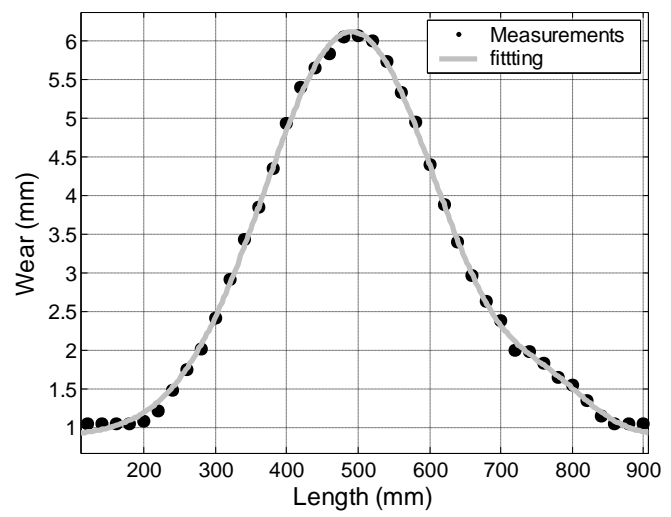

Figure 8. Measurement adjustment using an analytic curve

\subsection{Catenary models}

The contact wire which transmits the electric current to the pantograph strip through sliding contact is the main component of the catenary. In order to facilitate current collection, this wire must be hung parallel to the track running plane. This is achieved by using an upper cable called the carrying wire, which holds the contact wire in place with the help of other vertical cables called droppers (Figure 9), [1], [10], [11] and [12]. In direct current systems two contact wires are usually used, since the electric voltages are lower, which means greater intensity and therefore a larger conducting section.

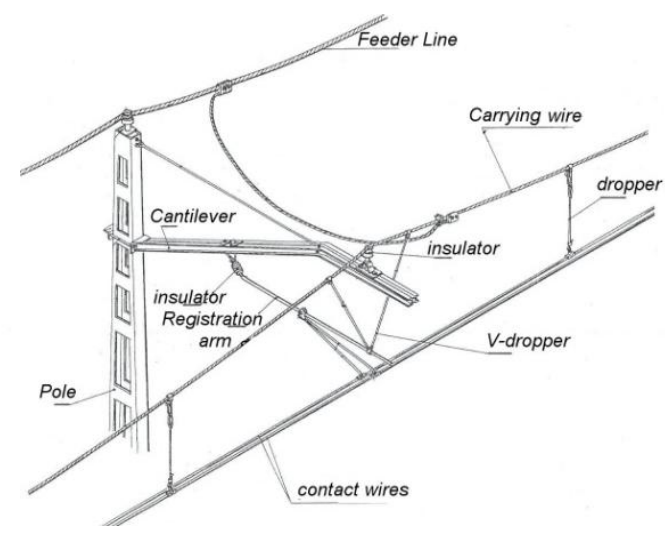

Figure 9. Flexible catenary elements

The dynamic-elastic behaviour of the catenary was characterised by using a numeric model based on the finite element technique. ANSYS, a thoroughly tested commercial tool, was used.

Unidimensional beam elements (BEAM3) were used to characterise traction and bending stiffness of the contact wire and the carrying wire. The droppers were characterised with bar elements (LINK10), which only work under traction and allow dropper slackening when faced with tensile forces. The clamps were defined using mass elements (MASS21). Finally, the registration arms were defined using an equivalent mass and stiffness, which at least let the first bending mode be taken into account.

The double contact wire models present an additional complication as they make the static equilibrium position difficult to calculate and require an additional contact element for the second wire.

For boundary conditions, clamps in the registration arms and at the ends of the carrying wire were defined. 
When the contact wire is excited, a wave is created that travels lengthways at great velocity and gradually becomes dampened as it advances. The wave bounces off the ends of the model, superimposing itself on the vibration of the wire. This phenomenon can alter the results of the simulation, which is why 5 spans have been defined in the final model, only taking account of the result obtained for the 3 central spans.

\subsubsection{Calculating the static equilibrium position}

Catenary design is focussed on getting correct line geometry that will ensure the horizontality of the contact wire. The horizontal position of the wire is obtained by the droppers being held firmly in position and longitudinal tensile forces applied to the wire. Fulfilling this design philosophy, the main geometrical design parameters are the length of the span, the number of droppers and their distribution, the height of the catenary, the initial maximum deflection of the contact wires and the wires section.

Dropper length, however, is not a design parameter but is determined by everything else. Although this value is essential for constructing the model, it is unknown data. To solve this problem, dropper length is determined by a static equilibrium calculation of the catenary, as described below:

1. The wire is set out in its theoretical position (horizontal or with maximum deflection), with sliding clamps at its ends and sliding supports in the position of the droppers. When the static equilibrium equations of the wire under its own weight have been solved, the reactions in the supports are equal to the dropper fastening forces.

2. Afterwards, an initially horizontal carrying wire is taken, with sliding clamps at its ends. Its static equilibrium position under the force of gravity is calculated and the previously calculated tension exerted by the droppers. At this stage, the weight of the droppers is not taken into account since their length is unknown.

3. Once the distortion of the carrying wire is known, the length and weight of the droppers is calculated. The weight of the droppers is added to the previous stage, which will change the position of equilibrium of the carrying wire.

4. This is repeated until the error is small enough.

\subsection{Pantograph models}

The pantograph (Figure 10) must keep in contact with the conductor wire and collect the current without any interruption. It comprises an articulated mechanism that adapts to the working height of the contact wire, ensuring vertical movement of its upper end. In the upper part a low inertia pantograph head is mounted joined to the main mechanism by a suspension that lets it adapt to the irregularities of the contact wire.
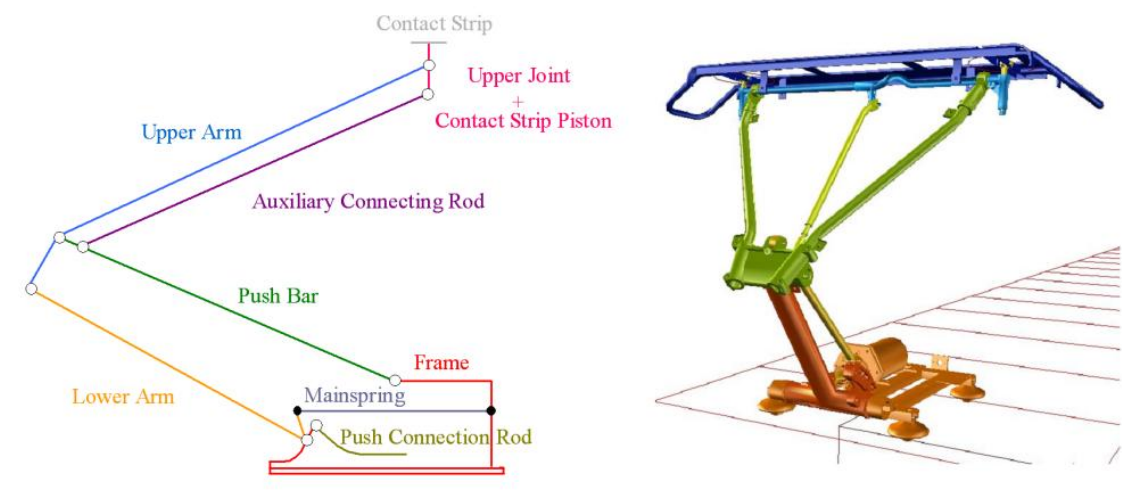

Figure 10. Pantograph 
The pantograph model has been defined, as is usual, by a lumped mass-spring mechanical system.

\subsection{Pantograph-catenary interaction models}

In order to analyse pantograph-catenary interaction dynamics the two previous models have been joined by a contact element (CONTAC175), defined between the contact wire and the collector strip mass, which moves forward at constant velocity. This element incorporates an internal spring that characterises the contact force, which is cancelled when there is loss of contact.

The final model has been validated according to standard EN 50318 [13].

One of the most interesting results of the dynamic simulations of pantograph-catenary interaction is the time history of the contact force, which enables current collection quality to be estimated. Due to the characteristics of this study, the stress distribution in the wire cross-sections is of greater importance.

\section{Incorporating singular spots into the models}

\subsubsection{Localised wear sections}

A zone of local wear has been included in the model. This singularity is defined as a progressive reduction in the cross section of the beam elements forming the wire. For this purpose, a special beam element has been used, which allows modelling of beams with variable section. Different values need to be defined for each beam section, for the parameters that characterise the behaviour of the beam to bending (area, centroid position, and area moments of inertia) (see Figure 11).

$$
\left.\begin{array}{l}
A=R^{2}\left(\pi-\alpha+0.5 \cdot \operatorname{sen} 2 \alpha-1,0743 \cdot 10^{-5} \quad\left(\mathrm{~m}^{2}\right)\right. \\
y_{C G}=\frac{2 R^{3} \operatorname{sen}^{3} \alpha}{3 A}-19,6724 \cdot 10^{-9} \quad(\mathrm{~m}) \\
I_{X}=\frac{R^{4}}{2}\left[\frac{\pi}{2}-\frac{\alpha+0.5 \cdot \operatorname{sen} 2 \alpha}{2}+\cos ^{3} \alpha \cdot \operatorname{sen} \alpha\right]-42,00 \cdot 10^{-12} \mathrm{~kg} \cdot \mathrm{m}^{2} \\
I_{Y}=\frac{R^{4}}{2}\left[\frac{\pi}{2}-\frac{\alpha-0.5 \cdot \operatorname{sen} 2 \alpha}{2}+\frac{\cos ^{3} \alpha \cdot \operatorname{sen} \alpha}{3}\right]-246.62 \cdot 10^{-12} \mathrm{~kg} \cdot \mathrm{m}^{2}
\end{array}\right\}
$$

Figure 11. Geometric properties of the worn section

Since the lower part of the sections is progressively reduced, its centroids cease to be lined up straight. To consider this effect, a special beam element was used (BEAM 189) that allows for warping of cross sections.

\subsubsection{Installation defects}

Another way to insert hard spots in the model consists in changing the original length of the droppers, thereby characterising any possible installation defects. A similar effect is obtained by inserting mass elements at intermediate points of the contact wire, characterising the splicing clamps used in repair operations to join a new section of wire to a section of old wire.

\subsection{Cases analysed}

Contact wire tensile stress was analysed for different states of wear, with a constant running speed of $70 \mathrm{~km} / \mathrm{h}$. The model corresponds to an actual section of non-compensated catenary installed on Line 
6. This section was chosen because of its reputation as a black spot where numerous wire replacement operations have been performed.. The features of this section (Figure 12) are:

- Span length: $30 \mathrm{~m}$

- Catenary height: $0.745 \mathrm{~m}$.

- Conductor sections: $153 \mathrm{~mm}^{2}$ (carrying wire) and $107 \mathrm{~mm}^{2}$ (contact wire)

- Tensile forces: $1200 \mathrm{kp}$ (carrying wire) y $900 \mathrm{kp}$ (contact wire). $(1 \mathrm{kp}=9.81 \mathrm{~N}$ )

- Dropper distribution: each span has ten droppers, with a distribution as shown in Table 1:

\begin{tabular}{|c|c|c|c|c|c|c|c|c|c|c|}
\hline Dropper & 1 & 2 & 3 & 4 & 5 & 6 & 7 & 8 & 9 & 10 \\
\hline $\mathrm{x}(\mathrm{m})$ & 3.5 & 6.5 & 9.0 & 11.5 & 14.0 & 16.5 & 19.0 & 21.5 & 24.0 & 26.5 \\
\hline
\end{tabular}

Table 1. Dropper positions in the modelled section

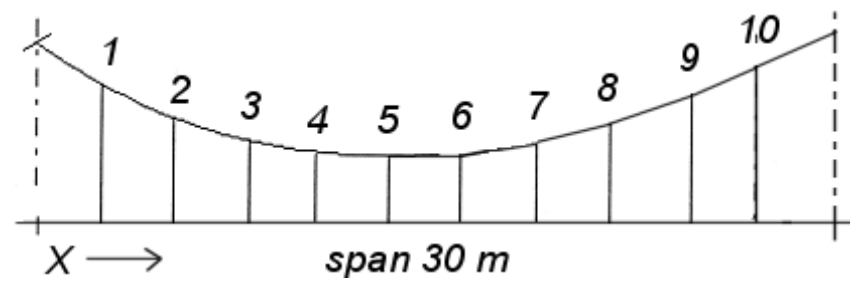

Figure 12. Diagram corresponding to a catenary span

The pantograph analysed is an ADtranz pantograph, of general use in Metro de Madrid. The model parameters (Figure 13) have been given by the manufacturer. These values are usually identified with experimental measurements of pantograph frequency response.

\begin{tabular}{|c|c|}
\hline Parameter & Value \\
\hline $\mathrm{m}_{2}$ & $13.8 \mathrm{~kg}$ \\
\hline $\mathrm{c}_{2}$ & $18000 \mathrm{~N} / \mathrm{m}$ \\
\hline $\mathrm{d}_{2}$ & 0 \\
\hline $\mathrm{m}_{1}$ & $8 \mathrm{~kg}$ \\
\hline $\mathrm{c}_{1}$ & 0 \\
\hline $\mathrm{d}_{1}$ & 0 \\
\hline $\mathrm{F}_{\text {friction }}$ & $2 \mathrm{~N}$ \\
\hline $\mathrm{F}_{\text {static }}$ & $98 \mathrm{~N}$ \\
\hline
\end{tabular}

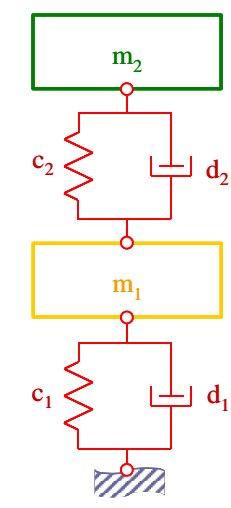

Figure 13. Pantograph features

\subsection{Preliminary studies}

Some preliminary studies were performed to define the final characteristics of the simulation models.

\subsubsection{Choosing the wear scenarios}

Different values have been tested for the parameters defining the wear function (eq. 1), with the purpose of obtaining different degrees of wear to include slight and severe wear. Finally, the degrees of wear shown in Table 2 were choosen, as they represent actual wear states. They are shown in 

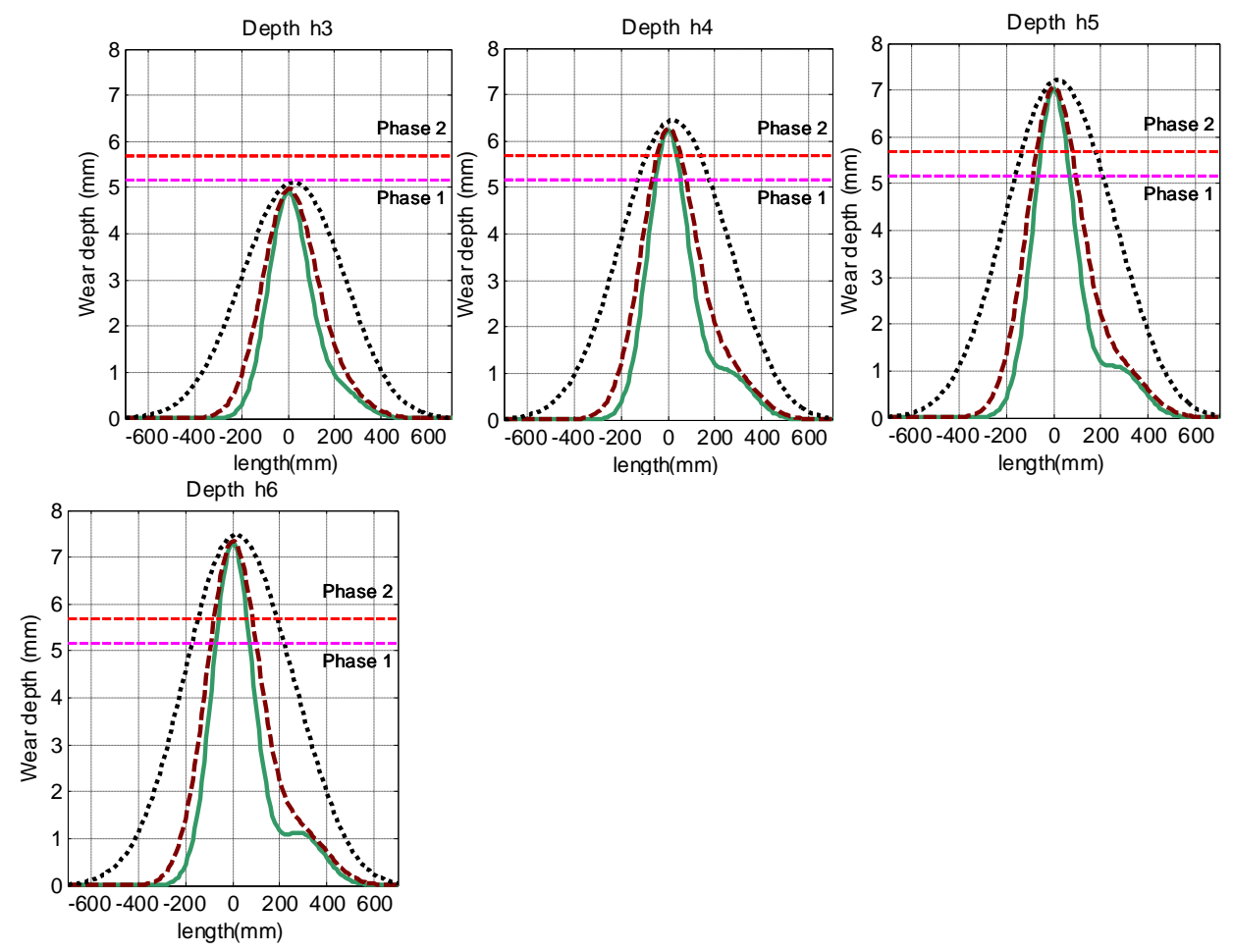

Width 1

- - Width 2

Width 3

Figure 14.

\begin{tabular}{|l|c|c|c|c|c|c|}
\hline & $\mathrm{h} 3$ & $\mathrm{~h} 4$ & $\mathrm{~h} 5$ & $\mathrm{~h} 6$ & Phase 1 & Phase 2 \\
\hline Depth (mm) & 5 & 6,5 & 7 & 7,5 & 5,18 & 5,68 \\
\hline Section loss $(\%)$ & 43,3 & 60,2 & 64,8 & 68,5 & 45,2 & 51 \\
\hline
\end{tabular}

Table 2. Degrees of wear
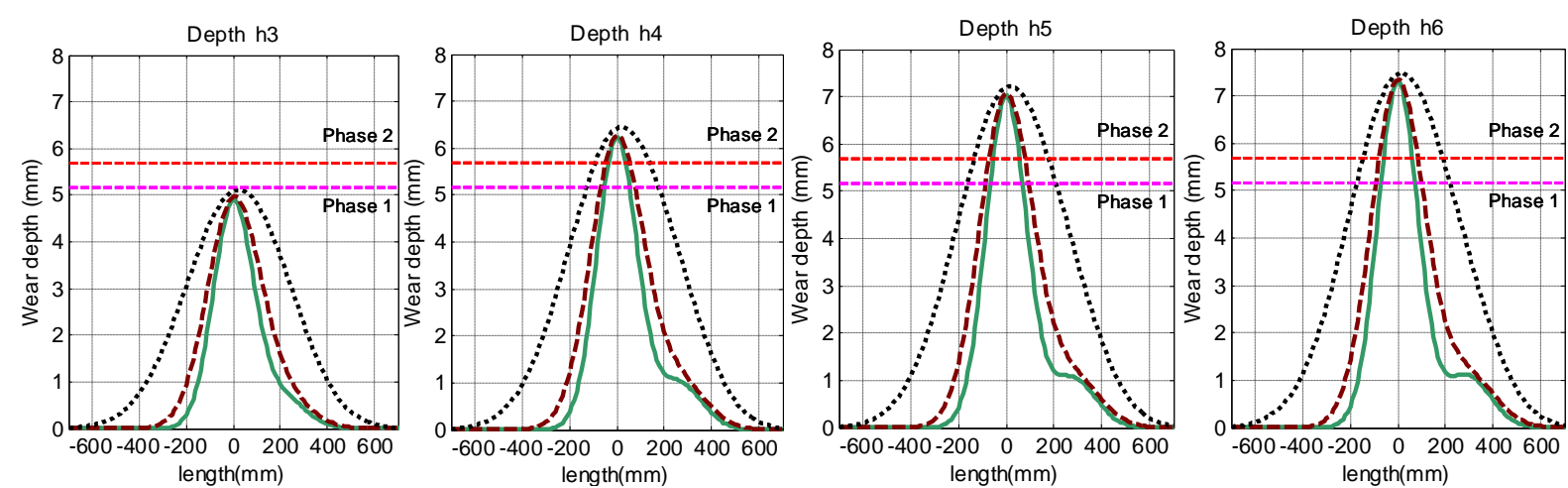

...... Width 1

- - Width 2

Width 3

Figure 14. Degrees of wear grouped by width. In colour, the different heights

In each case, the geometric properties that characterise bending behaviour for the different sections were calculated using expressions from equations in Figure 11. 


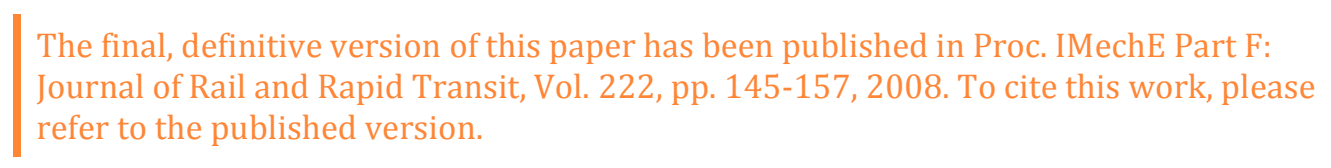

\subsubsection{Choosing the position of the worn zone}

Several dynamic simulations were performed, varying the position of the worn zone, in order to determine the zone where the passing of the pantograph causes greatest stresses in the wire.

Other specific defects were also included in the catenary in order to introduce hard spots and obtaining the worst possible scenario. The length of a dropper was shortened by $20 \mathrm{~mm}$ and a $700 \mathrm{~g}$ mass element was inserted into the contact wire. Various configurations were tested to determine which position was the least favourable for placing both types of defect, causing greater tensile stresses.

The wear zone and the defect elements were inserted into one of the contact wires (Figure 15).

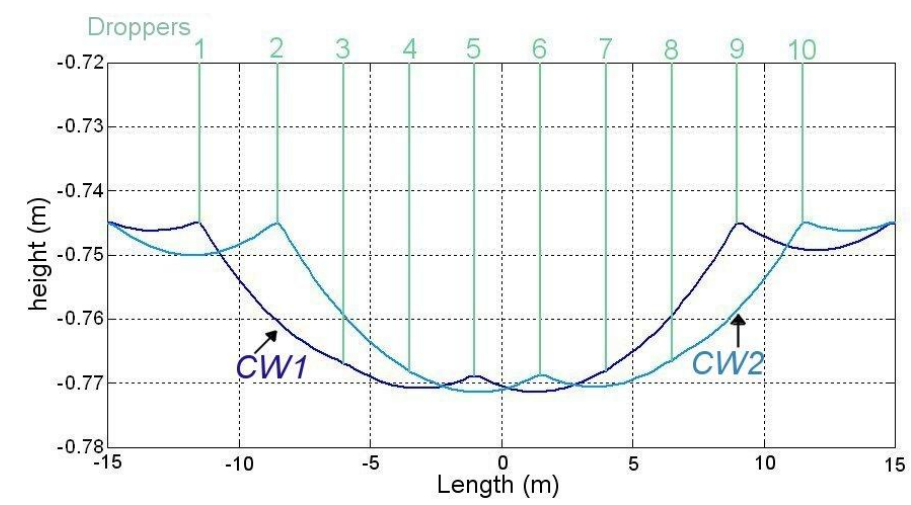

Figure 15. Equilibrium position of a conventional catenary span

The greatest stress was obtained by shortening dropper 3 (see Figure 15), located between the registration arm and the centre of the span. In the majority of the cases simulated, the maximum stress was reached $8 \mathrm{~cm}$ from this dropper, regardless of the position of the defect, for which reason the wear zone was inserted at this point. Although the increase in tension in respect of a defect-free catenary was $1.1 \%$, it was decided to shorten this dropper for the final simulations, without including the mass element.

\subsection{Contact wire wear regulations}

Allowable stress has been calculated in accordance with standard EN 50119 [14], which considers the ultimate tensile stress of material (copper C-1110) in order to take account of diverse factors such as the temperature of in-service wire or the features of the tensioning system. The standard also considers a wear coefficient, which has been omitted in this study as this effect was already included in the simulations. The allowable stress obtained after applying these coefficients, was:

$$
\sigma_{\text {admisible }}=\sigma_{\text {rotura }} \cdot k_{\text {temp }} k_{\text {desg }} k_{\text {carg } a} k_{\text {eff }} k_{\text {sust }} k_{\text {sold }}=0,81225 \cdot \sigma_{\text {rotura }}=290.7855 \mathrm{~N} / \mathrm{mm}^{2}
$$

\section{$4 \quad$ Results}

The results obtained can be presented in various ways. The most appropriate have been chosen for determining the minimum allowable section of contact wire.

\subsection{In the time domain}

\subsubsection{Contact force vs. time}

Figure 16 shows the evolution over time of the contact force with severe wear in dropper 3. 


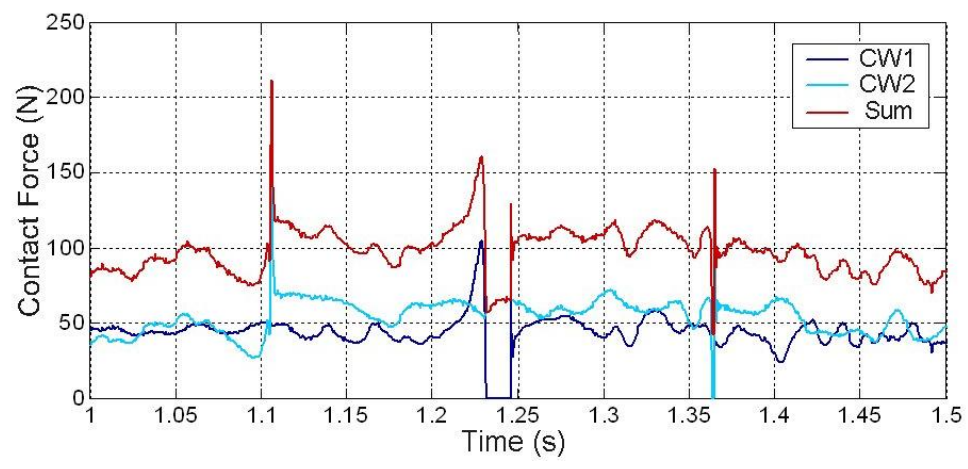

Figure 16. Detail of the evolution of contact force on passing through the wear zone

When the pantograph passes over the most worn section $(\mathrm{t}=1.23 \mathrm{~s})$, a contact loss takes place in the worn wire, the contact force becoming zero.

\subsubsection{Maximum tensile stress vs. pantograph position.}

Figure 17 shows maximum wire tensile stress according to the position of the pantograph. However, it does not indicate in which section of the wire this value is reached at every instant. Maximum tensile stress is usually reached in some section near to that most worn section, regardless of the position of the pantograph.

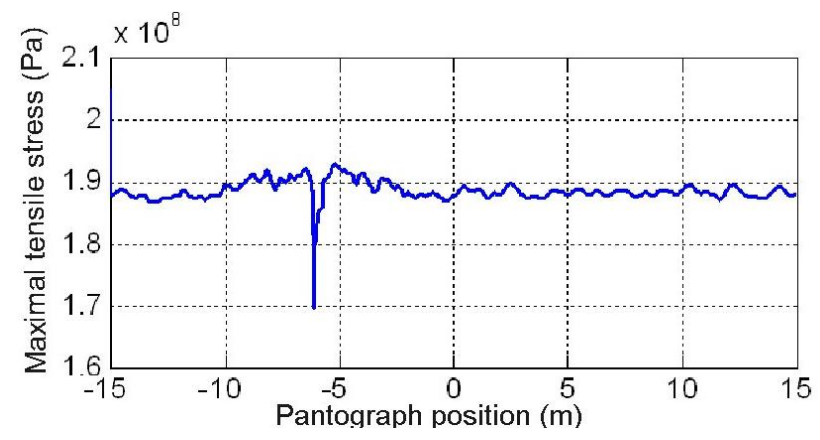

Figure 17. Maximum tensile stress reached at each instant

It can be seen that the maximum tensile stress remains practically constant; however, it is slightly greater in the worn zone. This result coincides with actual experience, as the wire usually breaks when the pantograph passes over it.

A falling peak can also be seen in the graph, which corresponds to a minimum in tensile stress at the precise moment the pantograph passes over the minimum section $(x=-6 \mathrm{~m})$. This behaviour can be justified if the worn zone is considered as a stress raising notch. When the pantograph is distant, the compensatory axial tensile force tends to open the notch. However, when the pantograph reaches the worn zone, it serves as a support for the wire, closing the notch and reducing the tensile stress.

\subsection{Wear level curves}

These graphics simultaneously show the results of several simulations. The ordinates axis shows the maximum stress obtained in any section of wire for any instant. Different parameters, such as wear depth, tensile force or contact wire stiffness can be shown on the abscise axis. Finally, different families of curves are used to represent each wear scenario.

It is of interest that the parameter represented on the abscise axis should be able to be easily measured so that these graphs can be used in a real situation. The wear geometry can be measured 
with an overhead line recording vehicle and interpolate between two of the families of curves represented. These graphs may then be used to determine if the tensile stress that is reached is above or below the allowable stress.

\subsubsection{Maximum tensile stress vs. wear depth}

The abscise axis represents wear depth (Figure 18). The level curves represent the wear widths studied. The wear depths associated with phases 1 and 2 of the go/no go gauges used in the visual inspections have also been represented (vertical reference lines), as well as the ultimate tensile stress of the material and the allowable stress stated in regulations (horizontal lines of reference).

This type of graph is highly useful for planning wire replacement operations as it enables priorities to be set for wire replacement depending on the depth and width of the worn zone. If the depth is the same, the most critical zones are those of least width.

The line corresponding to a1 width wear reaches the allowable stress for wear depths slightly above those marked by go/no go gauge phase 2 . Therefore, for this width, the gauge is appropriate and on the side of safety. For greater widths (a2 and a3), greater depths may be attained before reaching the allowable stress, which for case a3 would be greater than $7 \mathrm{~mm}$.
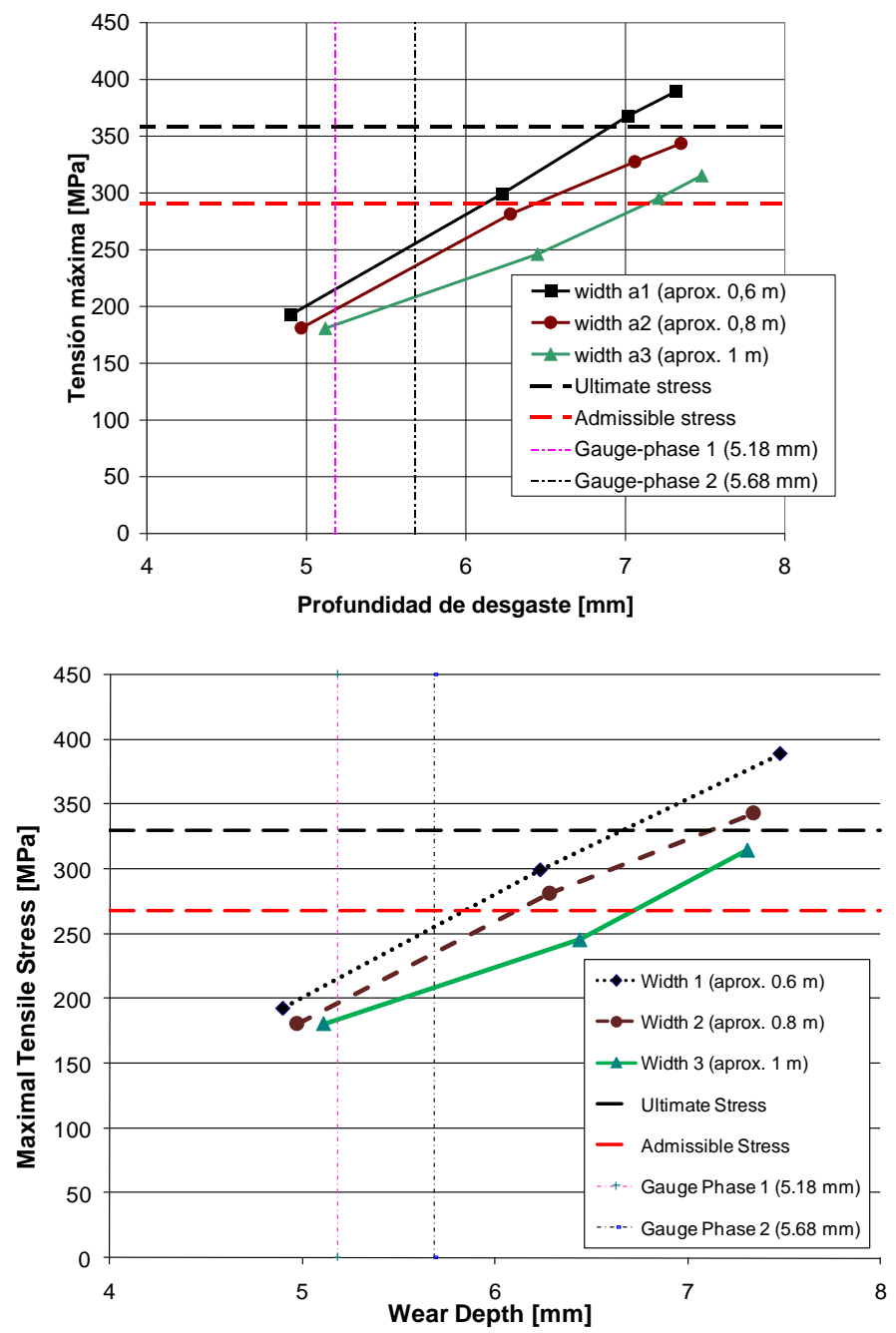

Figure 18. Representing maximum tensile stress against wear depth 


\subsubsection{Maximum tensile stress vs. contact wire tensile force}

It is also of interest to know how the maximum tensile stress evolves when the contact wire tensile force is varied. (Figure 19). The nominal tensile force of the catenary studied is $800 \mathrm{kp}(1 \mathrm{kp}=9.81 \mathrm{~N})$, although it can vary after being in service for some time with values of up to $900 \mathrm{kp}$ being admitted. This can be a decisive factor when prioritising wire replacement, instead of using only geometric wear measurement as a basis. However, the recording vehicle is unable to measure this parameter.

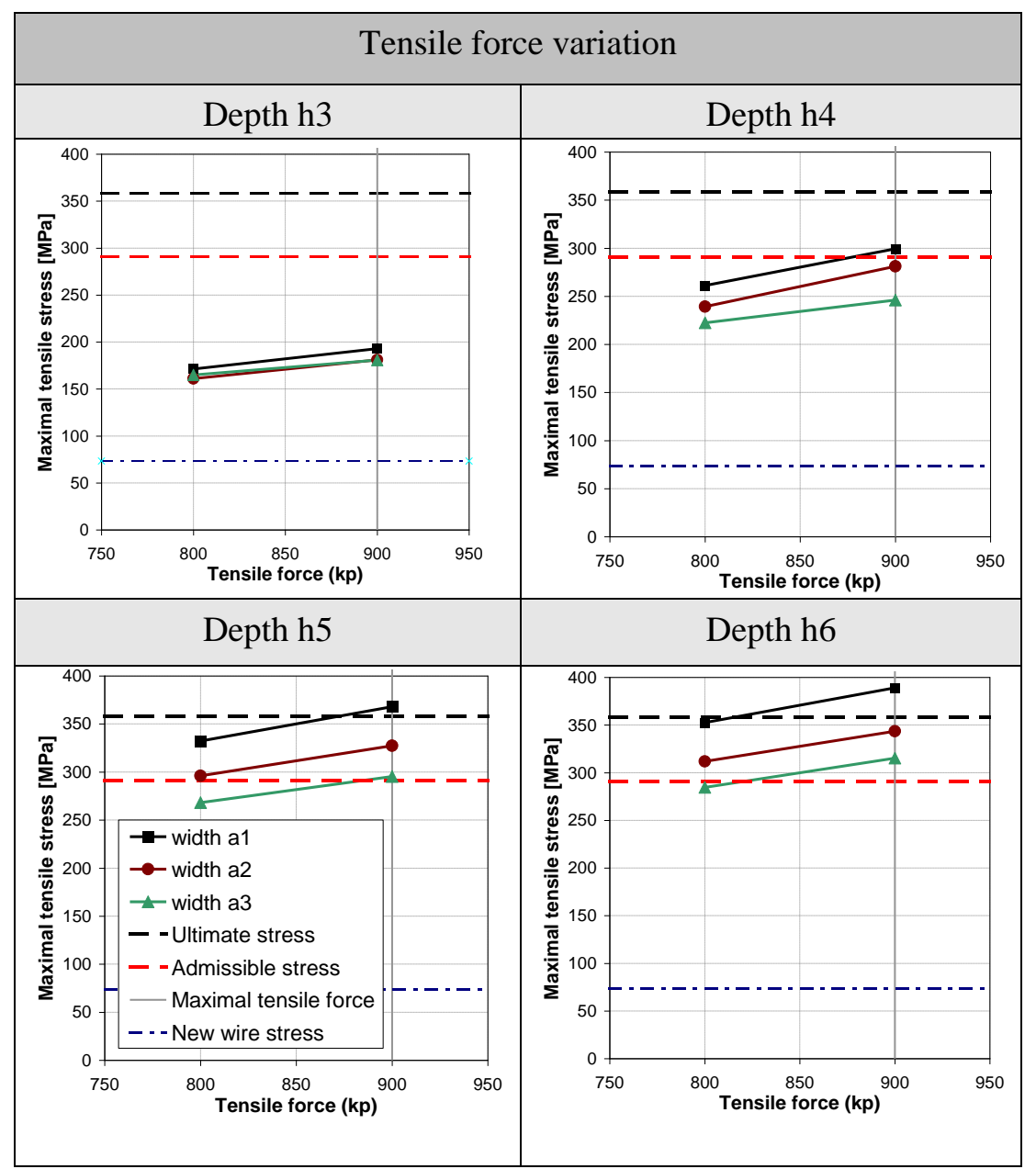

\section{Wear Profiles}
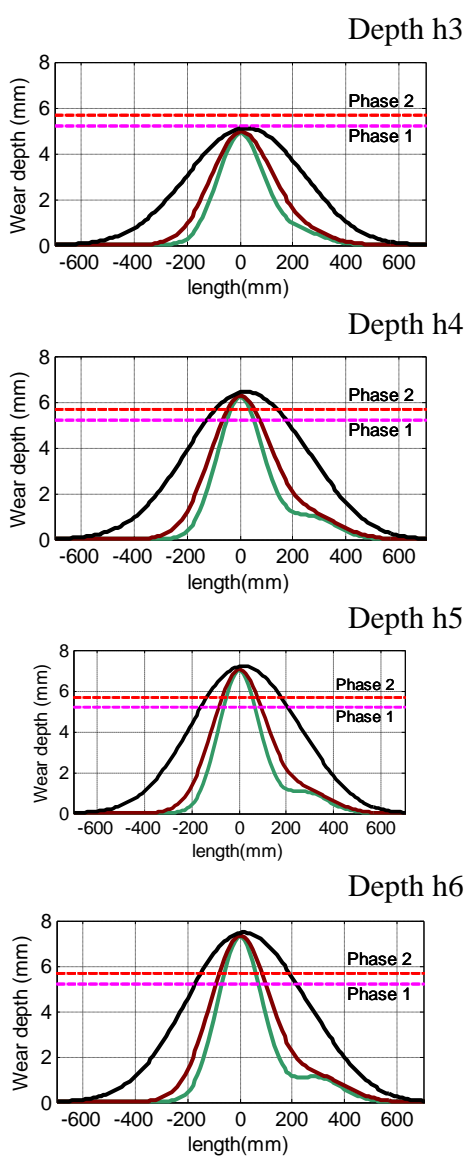

Figure 19.Tensile stress sensitivity (tensile force in $\mathrm{kp}, 1 \mathrm{kp}=9.81 \mathrm{~N}$ ) 

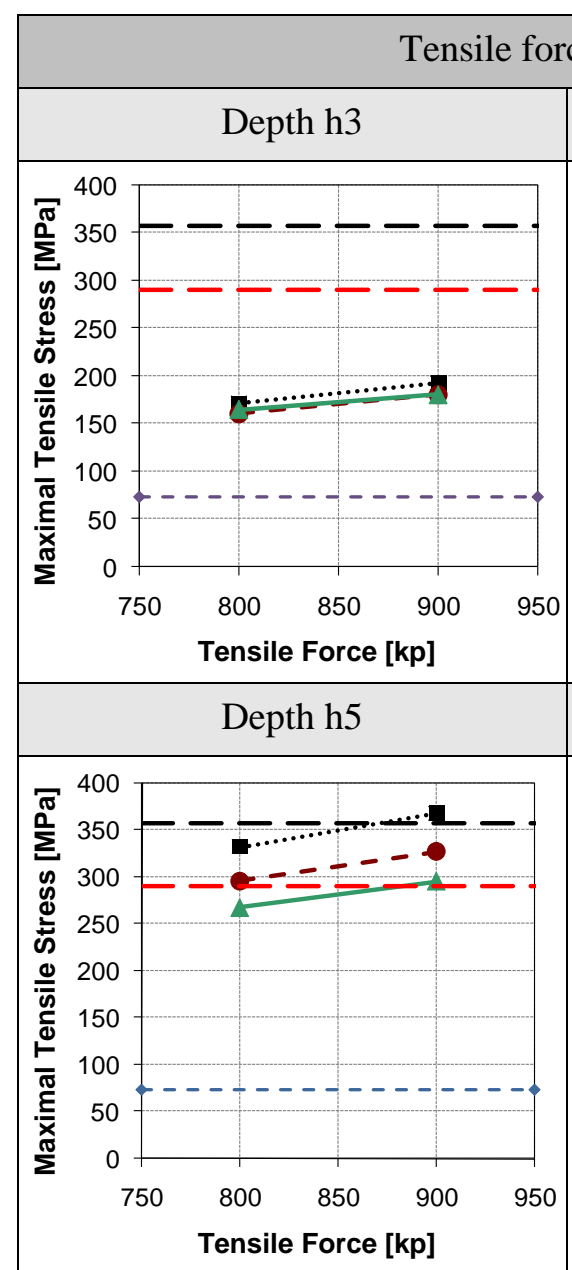

Depth h4

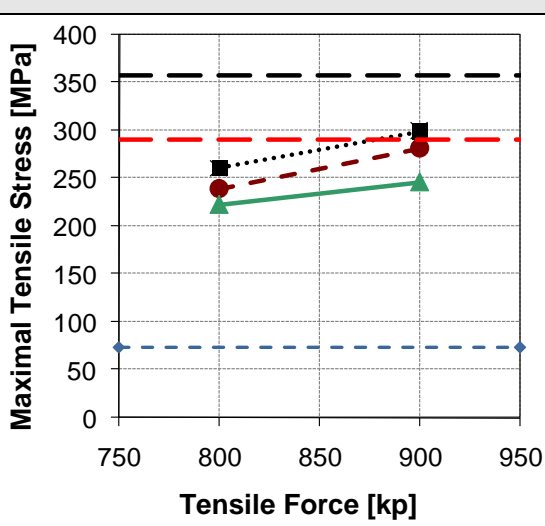

Depth h6

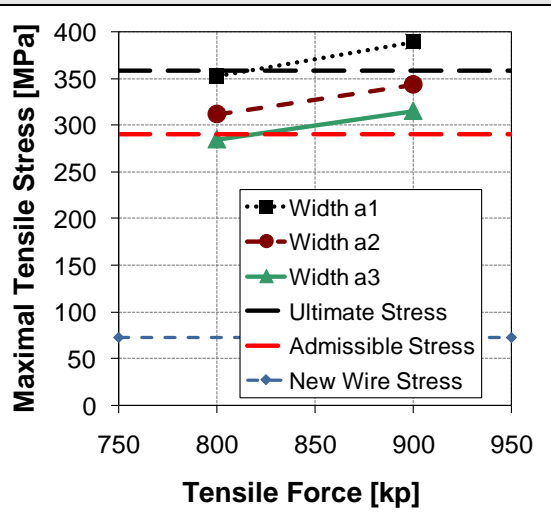

Wear Profiles

Depth h3

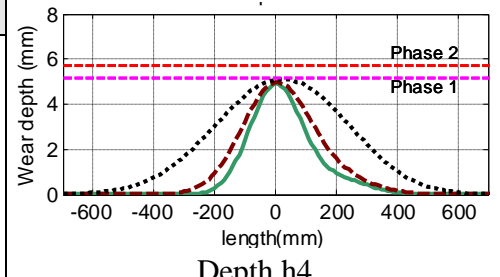

Depth h4

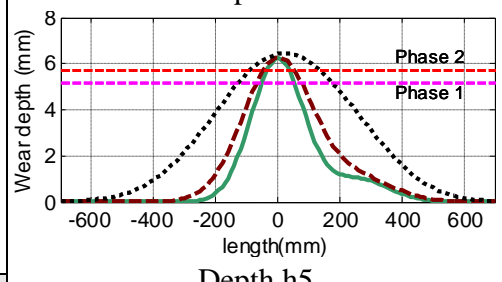

Depth h5

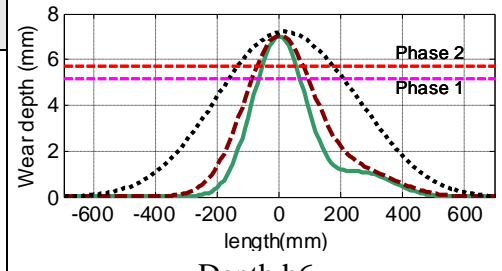

Depth h6

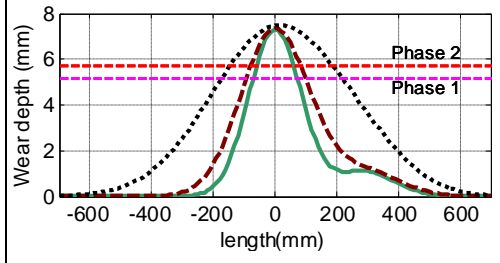

Figure 20.Tensile stress sensitivity (tensile force in $\mathrm{kp}, 1 \mathrm{kp}=9.81 \mathrm{~N}$ )

\subsubsection{Maximum tensile stress vs. contact wire stiffness}

Several models with different values of the contact wire stiffness were compared. Variations of the contact wire stiffness were obtained by modifying the tensile stress of the wire. Figure 21 shows the variation in tensile stress against contact wire stiffness. This stiffness can be calculated by dividing the contact force in each wire by the displacement undergone by this wire as the pantograph passes over it. However, in practice, the recording vehicle measures the total force applied to the two wires. For this reason, a fictional stiffness was used for each wire, dividing the total force of the pantograph by the displacement of each wire. Although this is not a real magnitude, it turns out to be just as useful as the actual stiffness. In order to work with a value that is representative of the passage over the wear zone, the mean value in a 2 metre window located on the maximum wear spot, has been used. 


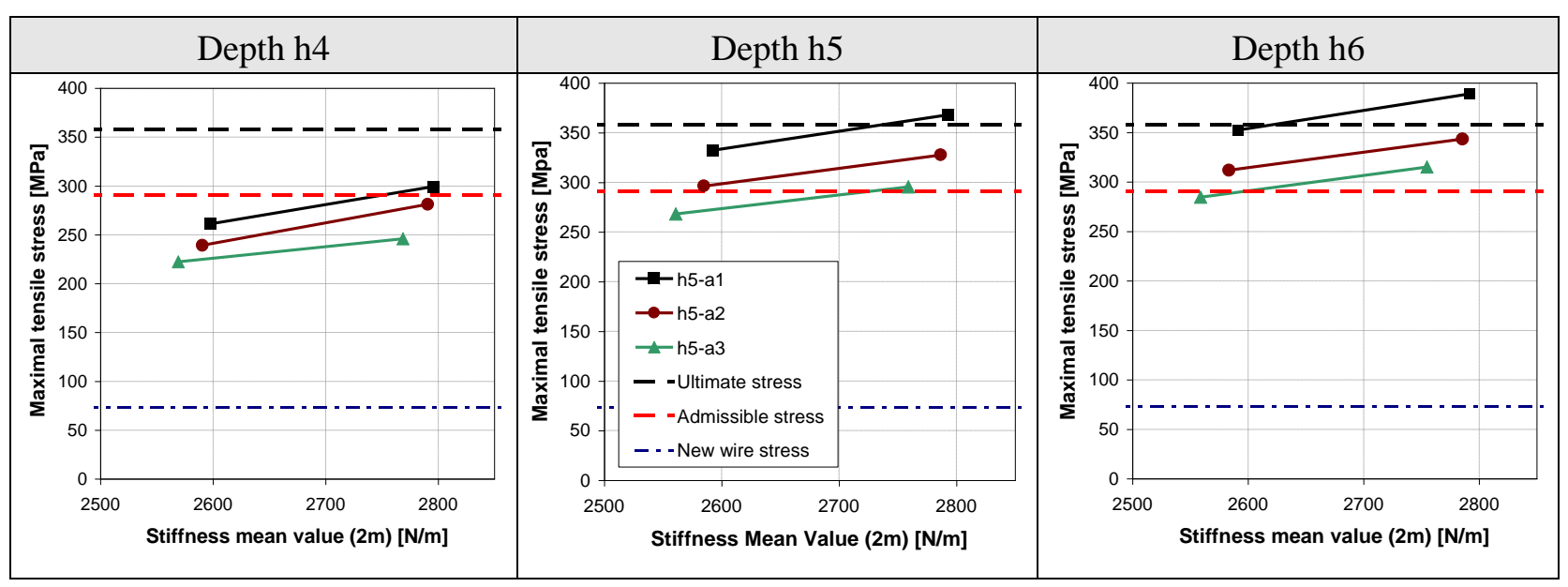

Figure 21. Contact wire stiffness sensitivity in conventional catenary (only worn wire)

These results are only valid for catenary having certain features, and could vary if the length of the span or the distribution of the droppers were other than what was considered in this study. It can be seen that as the wire stiffness increases, so does the maximum tensile stress, as would be expected.

\section{Conclusions}

A catenary model has been developed using finite elements. The model includes a local wear zone and a singularity in the contact wire, in order to simulate the worst case scenario from the tensile stress point of view. A system of masses and springs has also been incorporated into the model to represent the action of the pantograph, moving along the length of the contact wire at constant speed.

So as to be able to examine different stages in the process, different depths and widths were defined for the local wear zones. The results of the dynamic simulations performed for each state of wear enable the area of the minimum resistant section of the contact wire to be determined, which is that for which tensions greater than the allowable stress have been reached.

The maximum tensile stress reached in the contact wire shows a clear sensitivity to the size of the local wear zone, defined by its width and depth. It is, therefore, possible to assign a value for the maximum tensile stress depending on the size of the wear zone. In this way, on analysing the wear measurements recorded by the overhead line recording vehicle, the potential risk of wire breakage may be calculated. A strong dependence of the tensile traction forces of the contact wire has also been observed. These results make it possible to set priorities when it comes to replacing the most critical sections of wire, thereby making maintenance much more efficient.

The results obtained show that current wire replacement criteria are valid, although in some wear circumstances these criteria could be further adjusted to extend the life cycle of the contact wire.

\section{ACKNOWLEDGEMENTS}

The authors would like to express their gratitude for the kind help and invaluable advice given by Ignacio Fernández, Alejandro Chércoles and Gabriel Banzo (Metro de Madrid), during the preparation of this research work. Special thanks go to Javier Tomás and Fernando Pavón (Metro de Madrid), for the enormous contribution of information on the overhead line and for carrying out the laboratory tests, and to Benito Serrano (CITEF) for his contributions to the modelling process. 
This work would not have been possible without the initiative of our Director, Profesor Carlos Vera (CITEF), who introduced us to the principles of vehicle system dynamics.

\section{REFERENCES}

[1] Melis, M., González, F.J., "Ferrocarriles Metropolitanos. Tranvías, Metros Ligeros y Metros Convencionales", Colegio de Ingenieros de Caminos, Canales y Puertos, 2004. ISBN: 8438002870.

[2] Nagasawa, H. and Kato, K. "Wear Mechanism of Copper Alloy Wire Sliding Against Iron-Base Strip Under Electric Current", Wear, Vol. 216, pp. 179-183, 1998.

[3] Collina, A., Melzi, Stefano and Facchinetti, A., "On the Prediction of wear of contact wire in OHE lines: a proposed model", Vehicle System Dynamics Supplement Vol. 37, pp. 579-592, 2002.

[4] Bruni, S., Bucca, G., Collina, A., Facchinetti, A. and Melzi, S., "Pantograph-Catenary Dynamic Interaction in the Medium-High Frequency Range", Vehicle System Dynamics Supplement Vol. 41, pp. 697-706, 2004.

[5] Kubo, S. and Kato, K., "Effect of Arc Discharge on the Wear Rate and Wear Mode Transition of a Copper-Impregnated Metallized Carbon Contact Strip Sliding Against Copper Disk", Tribology International, Vol. 32, pp. 367-378, 1999.

[6] Bruno, O., Landi, A., Papi, M. and Sani, L., "Phototube sensor for monitoring the quality of current collection on overhead electrified railways", Proceedings of the Institution of Mechanical Engineers, Part F: Journal of Rail and Rapid Transit, Vol. 215, pp. 231-241, 2001.

[7] He, D. H., Manory, R. R. and Grady N., "Wear of Railway Contact Wires Against Current Collector Materials", Wear, Vol. 215, pp. 146-155, 1998.

[8] Kubo, S. and Kato, K., "Effect of Arc Discharge on Wear Rate of Cu-Impregnated Carbon Strip in Unlubricated Sliding Against Cu Trolley under Electric Current”, Wear, Vol. 216, pp. 172-178, 1998.

[9] Barmada, S., Landi, A., Papi, M. and Sani, L., "Wavelet multiresolution analysis for monitoring the occurrence of arcing on overhead electrified railways", Proceedings of the Institution of Mechanical Engineers, Part F: Journal of Rail and Rapid Transit, Vol. 217, pp. 177-187, 2003.

[10] Andrews, H. I., "Railway Traction: The Principles of Mechanical and Electrical Railway Traction”, Elsevier, 1986. ISBN: 0-444-42489-X.

[11] Kießling, F., Puschman, R., and Schmieder, A., "Contact Lines for Electric Railways: Planning, Design, Implementation”, Publicis, 2001. ISBN: 3-89578-152-5.

[12] Gonzalez, F.J. and Fuentes, J. (Coord.), "Ingeniería Ferroviaria", UNED, October 2006, ISBN: ISBN: 84-362-5293-4.

[13] EN 50318:2002, "Railway applications - current collection systems - validation of simulation of the dynamic interaction between pantographs and overhead contact line", 2002, ISBN: 0580405605 .

[14] EN 50119:2001, "Railway applications - Fixed installations - Electric traction overhead contact lines”, 2001, ISBN: 0580383016. 